\title{
Percepção de puérperas sobre a escolha da via de parto em um hospital da serra do Rio Grande do Sul
}

\author{
Women that have recently given birth's perception about the the choice of route of birth \\ delivery in mountain range of Rio Grande do Sul
}
Percepción de las puérperas acerca de la vía de nacimiento elegida en un hospital en la sierra del Rio Grande do Sul

Patrícia de Oliveira Schutz ${ }^{1 *}$, Mariana Bello Porciuncula1.

\begin{abstract}
RESUMO
Objetivo: Analisar os motivos determinantes sobre a via de parto para puérperas atendidas em um hospital da serra do Rio Grande do Sul. Métodos: Trata-se de um estudo de caso qualitativo desenvolvido na Unidade de Internação Obstétrica de um hospital geral. As participantes foram 22 puérperas, submetidas a partos normais ou cesarianas no período de julho a agosto de 2017, com idade igual ou superior a 18 anos. A análise de dados foi realizada segundo categorizações. Resultados: Para a discussão foram propostas duas categorias temáticas, são elas: "não deu para ser normal" e "influências relacionadas à via de parto: será mesmo uma escolha?". A maioria das puérperas relataram preferência pelo parto vaginal, mas $90,9 \%$ das entrevistadas foram submetidas à cesariana. Foram citados como fatores determinantes na escolha pelo tipo de parto a experiência anterior, orientações no pré-natal, desejo de fazer a laqueadura, medo, influências médicas, de familiares e amigos. Conclusão: A maioria das entrevistadas relataram que a via de parto em que foram submetidas não foi a desejada, ou que não tiveram opção em relação à escolha.
\end{abstract}

Palavras-chave: Comportamento de escolha, Preferência do paciente, Parto normal, Cesárea.

\begin{abstract}
Objective: To analyze the determining reasons that determine the choice of route of delivery for women that have recently given birth at the maternity of a hospital in the mountain range of Rio Grande do Sul. Methods: This is a qualitative case study developed at the Obstetric Unit of a general hospital. The participants were 22 postpartum women who underwent normal or caesarean section deliveries from July to August 2017, aged 18 years or older. Data analysis was performed according to categorizations. Results: For the discussion, two thematic categories were proposed: "It could not be normal" and "Influences related to the mode of delivery: is it choice?". Most postpartum women reported preference for vaginal delivery, but $90.9 \%$ of respondents underwent cesarean section. Determining factors in choosing the type of delivery were a previous experience, prenatal counseling, and desire for tubal ligation, fear, medical, family and friends influences. Conclusion: Most of the interviewees reported that the route of delivery that they were submitted was not which one they desired, or that they had no choice about it.
\end{abstract}

Key words: Choice behavior, Patient preference, Natural childbirth, Cesarean section.

\section{RESUMEN}

Objetivo: Analizar las razones determinantes de la elección de la vía de nacimiento para las mujeres atendidas en una maternidad de un hospital en la sierra del Rio Grande do Sul. Métodos: Se trata de un estudio de caso cualitativo desarrollado en la Unidad de hospitalización obstétrica de un hospital general. Las participantes fueron 22 mujeres posparto que se sometieron a partos normales o por cesárea de julio a agosto

\footnotetext{
${ }^{1}$ Universidade do Vale do Rio dos Sinos (UNISINOS), São Leopoldo/RS.

*E-mail: patriciaoliveirasch@hotmail.com
} 
de 2017, de 18 años o más. El análisis de los datos se realizó según las categorizaciones. Resultados: Se propusieron dos categorías temáticas para la discusión, a saber: "no podría ser normal" e "influencias relacionadas con el modo de entrega: ¿es realmente una elección?". La mayoría de las puérperas informaron preferencia por el parto vaginal, pero el $90,9 \%$ de las encuestadas se sometieron a cesárea. Los factores determinantes para elegir el tipo de parto fueron experiencia previa, asesoramiento prenatal, deseo de ligadura de trompas, miedo, influencias médicas, familiares y amigos. Conclusión: La mayoría de las entrevistadas informaron que la vía de nacimiento que fueron sometidas no era la que deseaban, o que no tenían otra opción al respecto.

Palabras clave: Conducta de elección, Prioridad del paciente, Parto normal, Cesárea.

\section{INTRODUÇÃO}

A preferência pelo tipo de parto, normal (vaginal) ou cirúrgico (cesárea), é assunto difícil e polêmico (MANDARINO NR, et al., 2009). Geralmente as mulheres buscam opiniões a respeito da melhor via de parto com o propósito de averiguar as vantagens e desvantagens associadas às possibilidades, procurando encontrar o que encaixa em suas expectativas. Em muitos casos a gestante nem mesmo participa da escolha da via de parto, sendo comunicada apenas sobre a decisão médica (SILVA SPC, et al., 2014).

A opção pela via de parto é uma decisão que perpassa uma série de aspectos, tais como as potenciais complicações, os benefícios associados à mesma, seus riscos, e até mesmo possíveis consequências futuras dessa escolha. Ainda, sabe-se que, apesar da oferta de informação estar cada dia mais disponível, é importante que as mulheres possam conhecer e utilizar os dispositivos citados na Rede Cegonha como elementos que contribuem na humanização do parto, destacando-se nesse contexto o direito pela livre escolha da via de parto, o qual deve ser respeitado (BRASIL, 2011).

Segundo a Organização Mundial de Saúde (OMS), a finalidade da assistência ao parto é manter mulheres e recém-nascidos sadios, com o mínimo de procedimentos intervencionistas, buscando garantir a segurança de ambos. Portanto, a OMS sugere que o profissional de saúde interfira no nascimento de uma criança somente quando necessário. Apesar dessa recomendação, os índices do parto cesáreo estão aumentando em diversos países (OMS, 2015).

Em relação à escolha da via de parto, estudos apontam que a falta de informações e a carência no atendimento durante o pré-natal levam a gestante a preferir por uma cesariana. As mulheres ainda se sentem inseguras por parirem por via vaginal, principalmente por temerem as consequências que podem resultar desta via de parto, como o surgimento de incontinência urinária e fecal, distopias genitais, lacerações perineais, deformação do corpo e influência na vida sexual como a perda do prazer em função das alterações ocorridas durante o parto, consequências essas de pequena incidência, mas que acabam por amedrontar a mulher ao optar pela via de parto (SILVA SPC, et al., 2014).

O possível despreparo das mulheres para o parto vaginal também pode minimizar a confiança na capacidade de ser protagonista para escolha da via de parto. Estes medos podem ser aumentados pelo desconhecimento, falta de rede de apoio, por influência da mídia, ou mesmo pela falta de diálogo com os profissionais de saúde que as acompanham no pré-natal (WEIDLE WG, et al., 2014). Nesse sentido, uma maior aproximação entre o profissional e a paciente é recomendada, com o objetivo de fornecer orientações que minimizem a ansiedade e insegurança dessas mães ao longo da atenção pré-natal (SILVA SPC, et al., 2014).

Diante destes fatos surge a seguinte questão de pesquisa: qual o motivo da escolha do tipo de parto pelas mulheres? Nesse sentido, o objetivo desse estudo foi analisar os motivos determinantes sobre a via de parto para puérperas atendidas em um hospital da serra do Rio Grande do Sul.

\section{MÉTODOS}

Trata-se de um estudo de caso, com abordagem qualitativa. $O$ estudo de caso qualitativo é rico em dados descritivos e focaliza a realidade de forma complexa e contextualizada (LÜDKE M e ANDRE MDEA, 2013). 
O Hospital no qual esse estudo foi realizado fica na serra do RS, caracterizando-se como entidade filantrópica, com 80 leitos, e atendimentos pelo Sistema Único de Saúde (SUS), convênios e particular. No ano de 2016 foram de 509 nascidos vivos, sendo desses 86 de parto vaginal e 423 de partos cesáreos. A presente pesquisa foi desenvolvida na Unidade de Internação Obstétrica do referido hospital.

As participantes foram 22 puérperas que se encontravam na unidade de internação obstétrica após nascimento de seus filhos, no período da coleta de dados, e que aceitaram participar da pesquisa, mediante assinatura do Termo de Consentimento Livre e Esclarecido. Para a constituição da amostra foi utilizado o critério de saturação de dados de Denzin NK e Lincoln YS (2005), que é a interrupção da inclusão de novos participantes assim que os dados obtidos apontassem uma certa repetição, não sendo pertinente dar continuidade na coleta.

A coleta de dados foi realizada por meio de entrevista semiestruturada, no período de julho a agosto de 2017. Foram incluídas no estudo mulheres submetidas a partos normais ou cesarianas, eletivas ou de urgência, no período da coleta de dados, com idade igual ou superior a 18 anos. Foram excluídas as que não tivessem em condições clínicas e psicológicas de responder as questões, os casos de óbito fetal, mães de fetos com peso inferior a 500 gramas e/ou com idade gestacional inferior a 22 semanas.

A presente pesquisa foi aprovada no Comitê de Ética em Pesquisa da Universidade do Vale do Rio dos Sinos, parecer número 2.149.929, e registrada na Plataforma Brasil sob número CAAE 69200017.3.0000.5344. Para garantir o anonimato das participantes do estudo, a identificação das mesmas foi feita com a letra "E", seguida do número da entrevista segundo a ordem de realização.

\section{RESULTADOS E DISCUSSÃO}

O caso em estudo no presente artigo referiu-se às escolhas relacionadas à via de parto por mulheres que tiveram seus filhos em um hospital da serra gaúcha. Para o entendimento dessas potenciais escolhas optouse primeiramente por apresentar as participantes do estudo, para após discutir os achados decorrentes das entrevistas realizadas.

As participantes do estudo foram 22 puérperas, com idade que variou entre 18 e 40 anos, tendo uma idade média de 29,5 anos. A maioria (17) das entrevistadas residem na cidade de Gramado e as demais (5) em cidades vizinhas, Canela (3) e São Francisco de Paula (2). Quanto ao nível de escolaridade das puérperas: duas tinham o ensino fundamental incompleto, onze tinham o ensino médio completo, três o ensino médio incompleto, três o ensino superior incompleto e três com ensino superior completo. Quanto ao regime de internação hospitalar, 11 puérperas estiveram internadas de forma particular/convênio e 11 puérperas foram hospitalizadas via SUS.

Da totalidade de mulheres incluídas neste estudo 4 (18\%) eram primíparas e 18 (82\%) eram multíparas. Em relação à idade gestacional no momento do nascimento, identificou-se que duas puérperas $(9,1 \%)$ tiveram os bebês com 37 semanas, seis delas $(27,3 \%)$ com 38 semanas, onze (50\%) com 39 semanas e três (13,6\%) com 40 semanas. Todas as participantes do estudo relataram ter recebido assistência pré-natal, sendo que 19 (86\%) realizaram mais de 6 consultas, e 3 (14\%) realizaram apenas o mínimo recomendado pelo Ministério da Saúde (BRASIL, 2012) de 6 consultas.

A seguir estão apresentados os temas constituídos a partir da análise e interpretação dos dados, elaborados por meio das categorizações.

\section{Influências relacionadas à via de parto: será mesmo uma escolha?}

Segundo Pinheiro BC e Bittar CML (2012) a humanização do parto não se inicia somente no momento do parto, mas engloba todo o processo desde o início da gestação, estabelecendo um bom vínculo entre o profissional e a gestante, através de orientações sobre todo o processo, estimulando a autonomia e cidadania da mulher.

A falta de informações, as intervenções desnecessárias no trabalho de parto e a violência obstétrica transformam o momento que deveria ser natural em um procedimento desumanizado, sendo assim um grande 
número de mulheres acreditam que o parto cesáreo é melhor, e que sentirão menos dor (NASCIMENTO RRP, et al., 2015).

Outro aspecto refere-se à vulnerabilidade da mulher que, motivada pelo medo e preocupação em relação ao momento do parto, faz com que considere mais a opinião dos médicos, tornando-se muitas vezes submissas às escolhas desses profissionais, e na maioria das vezes nem mesmo questionando-os sobre a decisão clínica pela via de parto. (FEITOSA RMM, et al., 2017).

Foi possível verificar neste estudo que muitos profissionais tentam interferir na decisão de cada mulher, o que foi percebido nos seguintes depoimentos:

"Ele me induziu a cesárea, falou para mim fazer mesmo, que era melhor para mim, daí o segundo já estava cortado eu não ia querer tentar e essa terceira também, já sabia que ia ser, eles não fazem [...]". (E2).

"[...] ela me orientou [...] me disse que eu poderia sim ter um parto normal, mesmo após ter tido uma cesárea, que não teria complicação e nem nada, mas não me deu $100 \%$ de certeza, porque ela me disse que seria mais provável uma cesariana do que o normal[...]".(E4).

"[...] ele me deixou bem à vontade para escolher, só única coisa que ele disse que dependia se eu ia ter dilatação e se ia no caso ocorrer tudo bem, e teria que ver a possibilidade porque ela era muito grande [...]". (E5).

O profissional de saúde além de ter conhecimento técnico, necessita ser capacitado para reconhecer a singularidade de cada mulher, a cultura própria de cada uma. (WEIDLE WG, et al., 2014). Entretanto, muitas vezes ocorre insensibilidade dos profissionais em relação às necessidades de cada mulher no momento do parto. E percebe-se uma comunicação parcial, ou seja, a gestante não participa das discussões e escolhas sobre o momento do parto (NASCIMENTO RRP, et al., 2015).

No estudo de Pimenta LF, et al. (2013), em relação ao poder de decisão exercido pelo médico e pela gestante no momento da escolha da via de parto, as puérperas entrevistadas relataram que o médico tem o poder total de decisão, no entanto referiram que deveria ter sido levado em conta à opinião da mulher. Contudo, foi percebido a vulnerabilidade da mulher frente à decisão médica, que desconsidera o desejo da mulher, retirando-lhe sua autonomia. Conforme se constatou em alguns relatos, as puérperas referiram que alguns profissionais também realizaram orientações a favor do parto normal.

"Ele deu preferência pelo parto normal, é parto normal que eles fazem, até pela recuperação que é bem melhor, parto normal é bem melhor, cesárea é em últimos casos". (E11).

"Ela não me deu escolha, não me deixou escolher não, eu pedi para ela doutora vai ser normal? E ela me disse sim, se os outros três foram, esse vai ser normal também". (E7).

Os dados identificados nesse estudo confirmam os de Silva SPC, et al. (2014) sobre a importância da assistência profissional qualificada no processo de decisão pela escolha do tipo de parto, destacando que é no pré-natal que esses profissionais exercem papel essencial, orientando, esclarecendo sobre as vantagens e desvantagens de cada tipo de parto, apoiando a decisão de cada mulher.

De acordo com Domingues RMSM, et al. (2014), o pré-natal mostrou-se influente em relação à escolha da via de parto, comparando a escolha no início da gestação e o resultado final da escolha, verificou-se a predominância nas gestantes atendidas pela rede privada da escolha pelo parto cesáreo e que as mesmas mantiveram sua decisão até o momento o final da gestação. No entanto a maioria da rede pública optou inicialmente pelo parto vaginal, mas a grande parte resultou em parto cesáreo.

O momento do parto é envolvido por muitos mitos e crenças, pois nesse período correm inúmeras modificações biopsicofísicas na mulher. Normalmente a família e amigos geram grande influência na escolha pela via de parto, o que ocorre principalmente de mulher para mulher. A cultura e o histórico familiar 
influenciam no aspecto emocional, gerando maior medo e angustia em relação à gestação e ao parto. (BITTENCOURT; VIEIRA; ALMEIDA, 2013).

Segundo Bittencourt $F$, et al. (2013) mulheres que referiram histórico de parto normal sem intercorrências na família relatam preferência pelo parto vaginal, no entanto as que referiram histórico familiar de parto vaginal exaustivo, demorado e com muita dor optaram pela pelo parto cesáreo. Os relatos das puérperas neste estudo mostram que sofreram influência na tomada de decisão por pessoas de seu convívio cotidiano:

"O pessoal dizia, olha o normal é melhor, você sente as dores mais depois passa, é mais cômodo para você, você já sai caminhando[...] ". (E6).

"A familia sempre aconselhava, é melhor o normal, vem à dor, mas depois é melhor [...] minha mãe teve eu com parto normal, e para mim ela sofreu porque eu estava sentada e o médico fez nascer de parto normal e sentada, quase morremos nós duas lá em Santa Catarina, mas faz muito tempo. E depois os outros dois irmãos meus foi de parto normal e o último de parto cesárea porque ela fez ligamento, já aproveitou[...]. (E18).

Esta pesquisa também identificou o medo com um fator que interfere na escolha pelo tipo de parto, estando mais citado nas mulheres que optaram por parto cesáreo em detrimento do parto vaginal.

Muitas mulheres utilizam como elemento fundamental para justificar sua escolha e diferenciar o parto vaginal do cesáreo, o medo da dor. Sendo que os dois tipos de partos proporcionam alguma sensação dolorosa, e o que os diferenciam é a intensidade da dor e a comparação aos partos anteriores. (ROVERI LL e FONSECA MRCC, 2016; FEITOSA RMM, et al., 2017; FERREIRA JUNIOR AR, et al., 2017).

O medo da dor é citado com um dos fatores que contribui de maneira significativa para o aumento do número de partos por via cesárea, os dados mostram que das entrevistadas neste estudo, quatro puérperas que optaram pelo parto cesáreo, relataram ter escolhido essa via por medo da dor do parto vaginal.

"Escolhi a cesárea por medo, medo de sentir a dor. E a cesárea eu achei bem tranquilo, não senti quase dores [...]". (E2).

"[...] já queria o parto cesárea, assim eu tinha o desejo do parto normal, por conta da recuperação, mas em questão da dor preferi à cesárea, mil vezes a cesárea[...]". (E1).

"Desde o início quis cesárea, eu não queria parto normal porque eu tenho medo das dores... Parto normal as minhas duas primas passaram e elas relataram que na hora dói, mas depois é tranquilo, aí na verdade eu não sei. Não quis arriscar. (risos) [...]". (E17).

Outro aspecto destacado como influenciador da opção pela via de parto refere-se à opção pela esterilização definitiva. Por vezes as mulheres sob o desejo de não engravidarem novamente, optam por realizar a ligadura de trompas, o que acaba resultando em uma cesárea a pedido. (PÁDUA KS, et al., 2010; FERREIRA JUNIOR AR, et al., 2017).

Atualmente, e de acordo com a legislação vigente, somente mulheres com idade acima de 25 anos ou com mais de dois filhos vivos podem fazer a cirurgia. (BRASIL, 1996). Todavia, o Ministério da Saúde vem desestimulado a efetivação da laqueadura no parto cesáreo, pois na grande maioria, a cesariana ocorre de forma desnecessária, apenas para fins de esterilização (CARNEIRO LMA, et al., 2015). A opção por parto cesáreo ligado a laqueadura foi citado por apenas uma das entrevistadas:

"Fiz laqueadura, já aproveitei também. É, porque até então não era para ter mais bebê, estou tendo porque Deus quis, porque eu estava como um mioma no útero, iria retirar, mas Deus mandou um bebê, para não, de certo para curar o mioma e não ter problema mais. Na verdade, não foi uma escolha, porque eu queria fazer a laqueadura e porque eu já fiz 2 cesáreas também e as outras duas não foi por opções foi porque precisei[...]". (E14). 
A experiência anteriormente relatada pelas gestantes sobre o momento e o tipo do parto é decisiva na atual escolha pela via de nascimento. (FIGUEIREDO NSV, et al., 2010). Em relação ao parto, os dados nos mostram que a experiência anterior também foi um fator citado pelas puérperas na escolha pelo tipo de parto, mas que nem todas citaram este como um fator decisivo.

"O primeiro parto eu fui na cara e na coragem para ganhar parto normal só que chegando lá na hora eles me deixaram no trabalho da meia-noite até às 10 horas da manhã sentindo as contrações de 5 em 5 minutos... Resultado? A minha segunda eu não queria parto normal de jeito nenhum [...]". (E1).

[...] já é minha terceira cesárea [..] na verdade na escolha a gente foi pela primeira, na primeira eu queria parto normal, por que eu sei que é bem mais tranquilo, a gente sente aquela dor na hora e depois terminou não é tudo isso que a gente tem que passar, mas eu não tenho dilatação, não tenho abertura dos ossos [...]". (E12).

"Essa é minha segunda gestação, a outra gestação também foi parto normal, desde o início queríamos parto normal [...] tive uma experiência muito boa com meu primeiro filho, nessa segunda gestação sofri um pouco mais até $M$. nascer, nossa intenção era ter 3 filhos, mas no momento acredito que dois está bom, (risos)". (E8).

Os depoimentos apresentados corroboram os estudos de Silva SPC, et al. (2014), no qual as mulheres que já haviam tido a experiência anterior por via parto normal acreditavam ser a melhor forma, no entanto as que não possuíam esta experiência demonstraram muitas dúvidas e medo em relação a parir por esta via.

Já no estudo de Domingues RMSM, et al. (2014), as experiências prévias positivas em relação à cesariana foram citadas por apenas um número pequeno de entrevistadas, indicando que a experiência positiva nem sempre está ligada a esse tipo de parto. E as experiências negativas em relação ao parto normal foram apontadas como fatores desencadeante a uma futura cesariana, entretanto no referido estudo os autores observaram que menos de $5 \%$ das mulheres receberam práticas humanizadas durante o trabalho de parto.

\section{Não deu para ser normal}

Observou-se nesse estudo que a maioria das mulheres, tanto no âmbito privado como público, optaram pelo parto vaginal no início da gravidez, doze puérperas $(54,6 \%)$ relataram como escolha inicial o parto normal, sete $(31,8 \%)$ queriam desde o início o parto cesáreo e três $(13,6 \%)$ relataram que não tiveram escolha. Destas, 20 puérperas $(90,9 \%)$ foram submetidas ao final ao parto cesáreo e apenas $2(9,1 \%)$ ao parto normal.

Estes dados divergem em alguns pontos com a pesquisa realizada por Domingues RMSM, et al. (2014), onde verificou-se uma diferença entre as mulheres atendidas no setor público e privado, sendo que no setor público de saúde, a preferência inicial entre as gestantes é maior pelo parto vaginal e na rede privada, a preferência inicial entre as gestantes é pela cesárea, apresentando taxas superiores a $70 \%$ no final da gestação.

O presente estudo está em conformidade com o de Santana FA, et al. (2015) e Tostes NA e Seidl EMF (2016), no qual os autores citam uma maior preferência das mulheres pelo parto do vaginal, pelo motivo de um pós-parto mais tranquilo, com uma recuperação mais rápida. Contudo, algumas optam pelo parto cesáreo por acreditar que seja um processo menos doloroso, mas na verdade evidencia-se que aumenta o tempo de internação e recuperação pós-parto, afeta o início da amamentação e eleva os gastos para o sistema público de saúde. (SANTANA FA, et al., 2015).

Neste estudo verificou-se que inicialmente a gestante opta pelo parto vaginal, por reconhecê-lo como a melhor opção para a mãe e o bebê e pela rápida recuperação:

“[...] normal é muito melhor, a recuperação é mais rápida, o leite desce mais rápido, a dor é na hora, depois estamos bem, fora que há mais chances de o bebê nascerem mais saudáveis e ou terem menos complicações[...]". (E8).

[...] do normal é bem mais fácil do que a cesariana né, por que o parto da cesariana a recuperação é mais demorada [...]". (E7). 
Estes dados corroboram os estudos de Nascimento RRP, et al. (2015) onde os dados apontam que em dez mulheres do estudo (40\%) preferiram o parto normal, mas, foram submetidas ao parto cesáreo, nove (36\%) escolheram e obtiveram o parto normal, e cinco $(20 \%)$ escolheram e tiveram parto cirúrgico. O mesmo estudo relata que o parto vaginal é mais saudável por ser natural, onde a parturiente é a protagonista de todo o processo, no entanto na cesariana a mulher assume a postura passiva, perdendo parte do seu protagonismo.

Todavia muitas foram submetidas a outro procedimento e relataram alguns fatores utilizados como justificativa, outras referiram não terem tido escolha:

"[...] não deu para ser normal, não tive dilatação, tive contrações, mas não tive dilatação". (E1).

"[...] aí, eu queria parto normal desde o inicio só que daí último mês como eu tenho passado muito mal e não deu de dilatação teve que ser cesárea mesmo[...]". (E3).

"[...] eu queria parto normal desde o começo, só que devido como rompeu a bolsa e eu perdi todo o liquido, o médico não pode esperar porque se não a nenê ia faltar o ar, ia dar asfixia nela, até porque ela nasceu bem roxinha, já estava se passando, foi tudo muito rápido [...]". (E5).

A dinâmica uterina e a apresentação pélvica foram os fatores mais citados pelas entrevistadas, e são supostas indicações associadas à prevalência do parto cesáreo. Esses dados corroboram com o estudo de Osava RH, et al. (2011) e Sanches NC, et al. (2012), onde todos os casos de apresentação pélvica tiveram como resultado o parto cirúrgico.

$\mathrm{Na}$ apresentação pélvica o parto cesáreo tornou-se indicação absoluta para alguns médicos, no entanto sabe-se que está é uma situação onde pode se encontrar dificuldades no parto via vaginal, mas não é indicação absoluta para a cesariana. Outras condições como bolsa rota, variação na quantidade de líquido amniótico (oligodrâmnio e polidrâmnio), falta de dilatação do colo uterino, também são utilizados por alguns médicos como sendo motivos para cesariana (OSAVA RH, et al., 2011).

\section{CONSIDERAÇÕES FINAIS}

A realização do presente estudo possibilitou conhecer as particularidades associadas às opções pela via de parto de mulheres que tiveram seus filhos em um hospital da serra gaúcha, sendo possível observar que a maioria tinha como preferência inicial a via de parto vaginal, relacionada à recuperação pós-parto mais rápida, e amamentação precoce. Contudo, foi possível perceber que a maioria foi submetida ao parto cesáreo, até mesmo quando sua preferência era pelo parto normal.

\section{REFERÊNCIAS}

1. BITTENCOURT F, et al. Concepção de gestantes sobre o parto cesariano. Cogitare Enferm, 2013; 3(18): 515-520.

2. BRASIL. Lei no 9.263 de 12 de janeiro 1996. Regula o $\S 7^{\circ}$ do art. 226 da Constituição Federal, que trata do planejamento familiar, estabelece penalidades e dá outras providências.

3. BRASIL. Ministério da Saúde. Gabinete do Ministro. Portaria № 1.459, de 24 de junho de 2011. Institui no âmbito do Sistema Único de Saúde - SUS - a Rede Cegonha. Diário Oficial da União n.121, seção 1, p.109, 27/06/2011.

4. BRASIL. Ministério da Saúde. Secretaria de Atenção à Saúde. Departamento de Ações Programáticas estratégicas. Atenção ao pré-natal de baixo risco: manual técnico. 5. ed. Brasília, DF, 2012.

5. CARNEIRO LMA, et al. Parto natural x parto cirúrgico: percepções de mulheres que vivenciaram os dois momentos. Rev. Enferm. Centro Oeste Mineiro, 2015; 2(5): 1574-1585.

6. DENZIN NK, LINCOLN, YS. The Sage handbook of qualitative research. 3. ed. Califórnia: Sage, 2005; 1210p.

7. DOMINGUES RMSM, et al. Processo de decisão pelo tipo de parto no Brasil: da preferência inicial das mulheres à via de parto final. Cadernos de Saúde Pública, 2014; 30(1): 101-116.

8. FEITOSA RMM, et al. Fatores que influenciam a escolha do tipo de parto na percepção das puérperas. Revista de Pesquisa: cuidado e fundamental online, 2017; 9(3): 717-726. 
9. FERREIRA JUNIOR AR, et al. Discurso de mulheres na experiência do parto cesáreo e normal. Saúde.com, 2017; 13(2): 855-862.

10. FIGUEIREDO NSV, et al. Fatores culturais determinantes da escolha da via de parto por gestantes. Hu Revista, 2010; 36(4): 296-306.

11. LUDKE M, ANDRÉ MEDA. Pesquisa em educação: abordagens qualitativas. São Paulo: EPU, 2013; $128 p$.

12. MANDARINO NR, et al. Aspectos relacionados à escolha do tipo de parto: um estudo comparativo entre uma maternidade pública e outra privada, em São Luís, Maranhão, Brasil. Cadernos de Saúde Pública, 2009; 25(7): 15871596.

13. NASCIMENTO RRP, et al. Escolha do tipo de parto: fatores relatados por puérperas. Rev. Gaúcha Enferm, 2015; 36(spe): 119-126.

14. ORGANIZAÇÃO MUNDIAL DA SAÚDE (OMS). Declaração da OMS sobre taxas de cesáreas. Genebra, 2015.

15. OSAVA RH, et al. Caracterização das cesarianas em centro de parto normal. Revista de Saúde Pública, 2011; 45(6): 1036-1043.

16. PADUA KS, et al. Fatores associados à realização de cesariana em hospitais brasileiros. Rev. Saúde Pública, 2010; 44(1): 70-79.

17. PIMENTA LF, et al. Percepção de mulheres sobre a escolha da via de parto: estudo descritivo. Online Brazilian Journal Of Nursing, 2013; 12(1): 1-10.

18. PINHEIRO BC, BITTAR CML. Percepções, expectativas e conhecimentos sobre o parto normal: relatos de experiência de parturientes e dos profissionais de saúde. Aletheia, 2012; (37): 212-227.

19. ROVERI LL, FONSECA MRCC. Fatores que influenciam a gestante na escolha do tipo de parto em uma maternidade no interior de São Paulo. Revista Saúde, 2016; 10(3-4): 8-21.

20. SANCHES NC, et al. Perfil das mulheres submetidas à cesareana e assistência obstétrica na maternidade pública em Ribeirão Preto. Texto \& Contexto - Enfermagem, 2012; 21(2): 418-426.

21. SANTANA FA, et al. Fatores que influenciam a gestante na escolha do tipo de parto. Revista da Faculdade de Ciências Médicas de Sorocaba, 2015; 17(3): 123-127.

22. SILVA SPC, et al. Parto normal ou cesariana? Fatores que influenciam na escolha da gestante. Revista de Enfermagem da UFSM, 2014; 4(1): 1-9.

23. TOSTES NA, SEIDL EMF. Expectativas de gestantes sobre o parto e suas percepções acerca da preparação para o parto. Temas em Psicologia, 2016; 24(2): 681-693.

24. WEIDLE WG, et al. Escolha da via de parto pela mulher: autonomia ou indução? Cadernos Saúde Coletiva, 2014; 22(1): 46-53. 